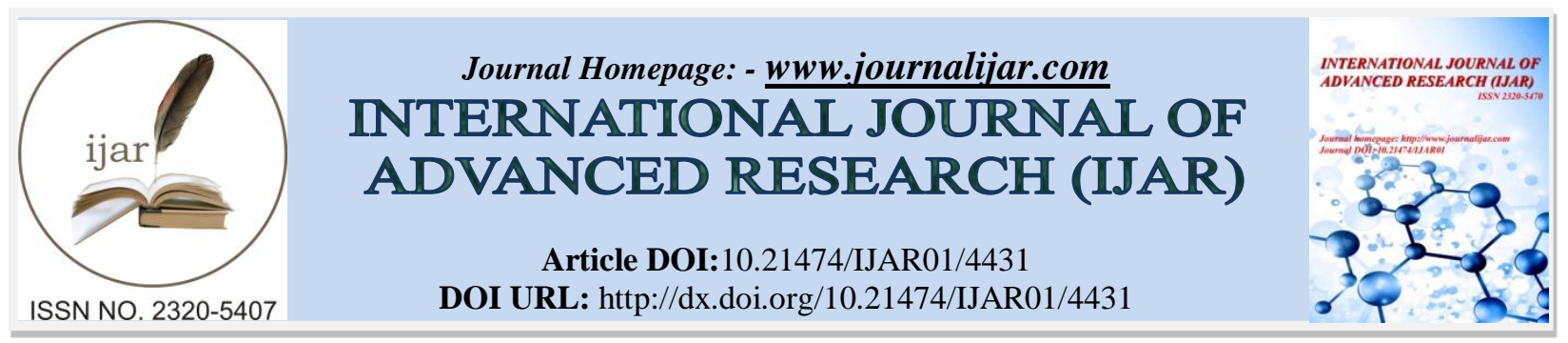

RESEARCH ARTICLE

\title{
THE ANTI-INFLAMMATORY EFFECTS OF TAIF PUNICA GRANATUM IN CYTOKINES PRODUCTION IN PBMCS OF PATIENTS WITH RHEUMATOID ARTHRITIS (RA).
}

\author{
Albogami Sarah. \\ Biotechnology Department, Faculty of Science, Taif University, 888-Taif, Kingdom of Saudi Arabia.
}

\section{Manuscript Info}

\section{Manuscript History}

Received: 10 April 2017

Final Accepted: 12 May 2017

Published: June 2017

Key words:-

Pomegranate, Inflammation,

inflammatory cytokines.

\section{Abstract}

Aim:Punica granatum L., generally known as pomegranate has been used for thousands of years to cure a wide range of diseases including rheumatoid arthritis (RA). This study examines Punica granatum extracts effect on cytokines production in PBMCs of patients with Rheumatoid arthritis (RA).

Materials \& methods: PBMCs were treated by $5-200 \mu \mathrm{g} / \mathrm{ml}$ of $P$. granatum methanol, aqueous, acetone, ethyl acetate extracts in realse of IFN- $\gamma$, IL-10, IL-4, and TGF- $\beta$ cytokines using ELISA.

Results: Methanol and aqueous $P$. granatum extracts suppressed IFN$\gamma$ release and enhanced IL-4 and IL-10 production, all the extracts enhanced the production TGF- $\beta$ from PBMCs of patients with Rheumatoid arthritis (RA).

Conclusion: Following treatment with $P$. granatum extracts cytokine production showed decrease of IFN- $\gamma$ release which is proinflammatory mediator, also raise of IL-4 and IL-10 production. It is also significantly increases TGF- $\beta$ release which is antiinflammatory cytokine.

Copy Right, IJAR, 2017,. All rights reserved.

\section{Introduction:-}

Inflammation is a biological process associated with the production of many factors, therefore suggesting that changes in gene expression could provide signatures at different phases or stages of inflammatory diseases such as rheumatoid arthritis (RA) [1]. Rheumatoid arthritis (RA) is a chronic, autoimmune disease in which the pathological immune reaction is believed to be started by the presentation of an (auto) antigen or super antigen by MHC class II positive cells to CD4 T cells[2]. These continuous immunological events could be investgated by the cytokines released at the different steps.Indeed, macrophage-derived cytokines for example tumour necrosis factor alpha (TNF- $\alpha$ ) and interleukin (IL)-1 play a key role in this process[3]. On the other hand, the role of $\mathrm{T}$ cells and their cytokines in the immune-pathogenesis of rheumatoid arthritis is not fully understood[4]. The balance of type 1 helper T cells (Th1) and type 2 helper $\mathrm{T}$ cells (Th2) subsets is involved in the regulation of several immune responses[5]. The type 1 helper T cells (Th1) cytokines, interferon gamma (IFN- $\gamma$ ) and TNF- $\alpha$ are vital for response versus intracellular infections, though the type 2 helper $\mathrm{T}$ cells cytokines such as IL-4, IL-5 and IL-10 are responsible for defence against extracellular infections. The type 1 helper $\mathrm{T}$ cells (Th1) cytokines have also been linked in the pathogenesis of autoimmune diseases, where a T-cell response versus a foreign self-antigen could play a key role [6]. In contrast, the type 2 helper $T$ cells (Th2) such as cytokines IL-4 and IL-10 downregulate inflammation [7]. 
The American College of Rheumatology advises the earliest potential diagnosis and treatment to boundary the degree of irreversible joint damage[8]. Present treatment medications are limited in their effectiveness and are often toxic. Several patients search for complementary and alternative medicine choices in coping with this disease. Studies have showed that patients suffering from chronic pain, such as in rheumatoid arthritis RA, and those displeased with existing treatment are very expected to look for alternate treatments, and an estimated $75 \%$ of patients with arthritis use complementary and alternative medicine [9]. Amongst the most extensively used treatments are herbal therapies [9]. Currently, the use of herbal products, because of their safety and effectiveness in the prevention and treatment of a number of chronic diseases, are being widely investigated worldwide [10]. The Punica granatum L., generally known as pomegranate an ancient fruit has been used since long in Middle Eastern medicine to prevent and treat a variety of ailments. These include anticancer, anti-inflammatory and anti-rheumatic activities [11]. In Ayurvedic medicine the pomegranate is believed "a pharmacy unto itself". For instance, the roots are used to treat helminthic disorder and the juice is considered as blood tonic [11]. Pomegranate additionally works as a medicine for diabetes [12]. The likely therapeutic properties of pomegranate include treatment and fighting cancer, cardiovascular disease, dental disorders, erectile dysfunction, and protection from ultraviolet radiation. Additional possible uses include Alzheimer's disease, arthritis, obesity and anti-inflammatory properties [13].

In this study, effects of methanol, aqueous, acetone, ethyl acetate $P$. granatum peelextracts wear investigated on the type 1 helper $\mathrm{T}$ cells (Th1) cytokine (Intracellular interferon-gamma (IFN- $\gamma$ ), the type 2 helper T cells (Th2) cytokines Interleukin-10 (IL-10) and Interleukin-4 (IL-4) andregulatory T cells cytokine (Transforming growth factor beta (TGF- $\beta$ ) production at the cellular levels in PBMC of patients with Rheumatoid arthritis (RA).

\section{Materials and Methods:- \\ Plant material:-}

Fully matured fruits of Pomegranates (Punica granatum L.) were collected in August 2016 during the harvest season from Al Hada local farm (Taif-Saudi Arabia). Plant species was taxonomically identified by the Biotechnology department, Taif University. Saudi Arabia.

\section{Preparation of Extracts:-}

The fruits were thoroughly washed with distilled water and hand-minced into small pieces to get peel. The peels were allowed to dry under shade in the laboratory for $20 \mathrm{~d}$. The dried peels were powdered by using electric blender, fine powder were used for extraction. The ethanol, acetone extract and ethyl acetate extracts were performed by using soxhlet apparatus. Twenty five gram of powdered peel material was extracted with of $100 \mathrm{ml} 100 \%$ methanol, $100 \%$ acetone, and e $100 \%$ ethyl acetaterespectively. The process of extraction carries on for 6 hours at $60^{\circ} \mathrm{C}$. The crude methanol extract was obtained after evaporated the ethanol to dryness at $40^{\circ} \mathrm{C}$ under reduced pressure. $100 \%$ Dimethyl sulfoxide (DMSO) was used to dissolve the dried extracts. For aqueous extract the fresh peel parts ( $25 \mathrm{~g}$ ) were macerated in $100 \mathrm{ml}$ deionized (DI) water and the solution was covered with aluminum foil and kept in a reciprocating shaker for $48 \mathrm{~h}$. The mixture was filtered with Whatman No. 1 filter paper and was lyophilized at $20^{\circ} \mathrm{C}$. Stock of $200 \mathrm{mg} / \mathrm{ml}$ was prepared for all extracts, styled using $0.22-\mu \mathrm{m}$ filters and used in the assays.

\section{Blood sampling, Isolation of Peripheral Blood mononuclear cells (PBMCs) \& treatment:-}

Blood samples were collected from patients with Rheumatoid arthritis (RA) and healthy controls. The samples were taken into a heparinised vials and mixed well by gently inverting the tubes several times. Human PBMCs were isolated by gradient centrifugation using Histopaque (Sigma Co., Poole, UK). Cells were then washed twice by centrifuge at $100 \mathrm{x}$ g for $10 \mathrm{~min}$ with sterile RPMI 1640 without fetal bovine serum. Medium were discarded and cell pellet were re-suspended in $1 \mathrm{ml}$ sterile roswell park memorial institute (RPMI) 1640. The cells viability and count were checked by using trypan blue and a haemocytometer. The cells concentration was adjust at $1 \mathrm{X} 10^{6}$ cells/ml and cultured into 6 well plates in RPMI 1640 complete medium containing 10\% fetal bovine serum ( FBS), $1 \mathrm{mM}$ L-glutamine, $10 \mathrm{mM}$ 4-(2-hydroxyethyl)-1-piperazineethanesulfonic acid (HEPES) buffer, $100 \mathrm{U} / \mathrm{ml}$ penicillin and $10 \mathrm{mg} / \mathrm{ml}$ streptomycin. After 24 hours of culture, cells were serum starved for additional 24 hours before they were treated with various concentrations of Pomegranates extracts $(5,10,50,100,200 \mu \mathrm{g} / \mathrm{ml})$, and cells were incubated for 48 hours at $37^{\circ} \mathrm{C}$ in a humidified incubator with $5 \% \mathrm{CO} 2$.

\section{Cytokine Assay:-}

Supernatants from PBMCs cultures were collected after treatment of the cells with different concentrations of pomegranates extracts and the samples were subsequently assayed in triplicates. The levels of IFN- $\gamma$, IL-4, IL-10 
and TGF- $\beta$ cytokines were determined using respective cytokine kits (OptEIA Human ELISA; BD Biosciences, CA, USA) according to manufacturer's instructions.

\section{Data Analysis :-}

Statistical analysis were performed using GraphPad Prism 6 (GraphPad Software). One-way analysis of variance (ANOVA) was use to analyze data. The p-values less than 0.05 were considered to indicate significant differences.

\section{Results:-}

Production of inflammatory cytokines were measured in vitro on PBMCs cell supernatant after being treated with $0.01-100 \mu \mathrm{g} / \mathrm{ml}$ of alcoholic and aqueous pomegranate extracts. Overall, the results showed that both extracts influenced cytokine production as follow:

\section{Intracellular interferon-gamma (IFN- $\gamma)$ :-}

The result showed that following treatment with $P$. granatum methanol and aqueous extracts, both extracts downregulated IFN- $\gamma$ production in PBMCs compared to untreated control cells (Figure 1 A\&B). At doses between $10-200 \mu \mathrm{g} / \mathrm{ml}$ of methanol extract and between $100-200 \mu \mathrm{g} / \mathrm{ml}$ of aqueous extract the production of IFN- $\gamma$ were statistically significant less. Effective dose for $P$. granatum methanol extract was $50 \mu \mathrm{g} / \mathrm{ml}$ and for $P$. granatum aqueous extract was $200 \mu \mathrm{g} / \mathrm{ml}$. Acetone and Ethyl acetate extracts showed no significant difference in IFN- $\gamma$ (Figure 1 C\&D) production compared to those of untreated cells (control).
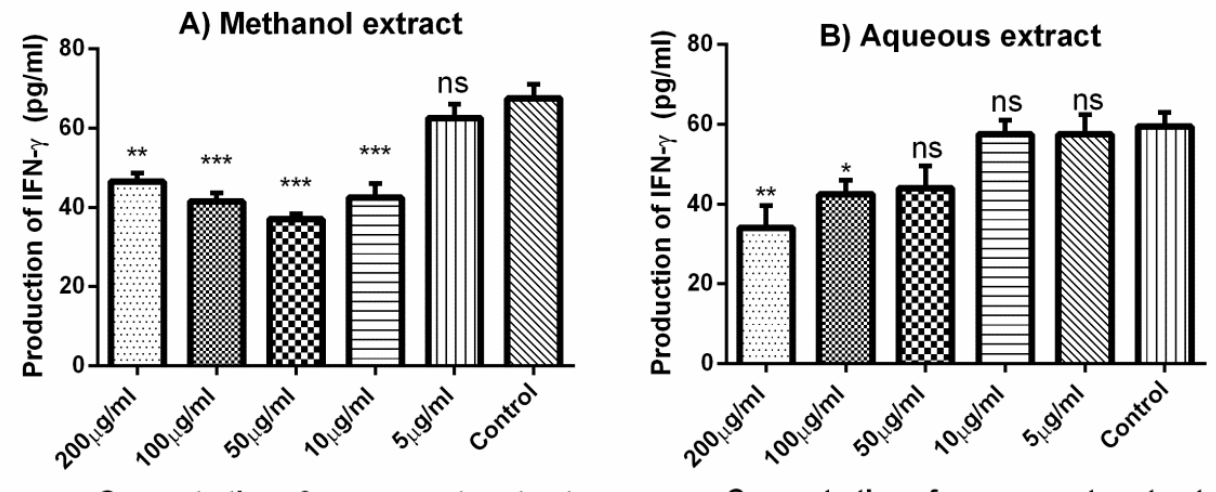

Concentration of pomegranate extract

Concentration of pomegranate extract
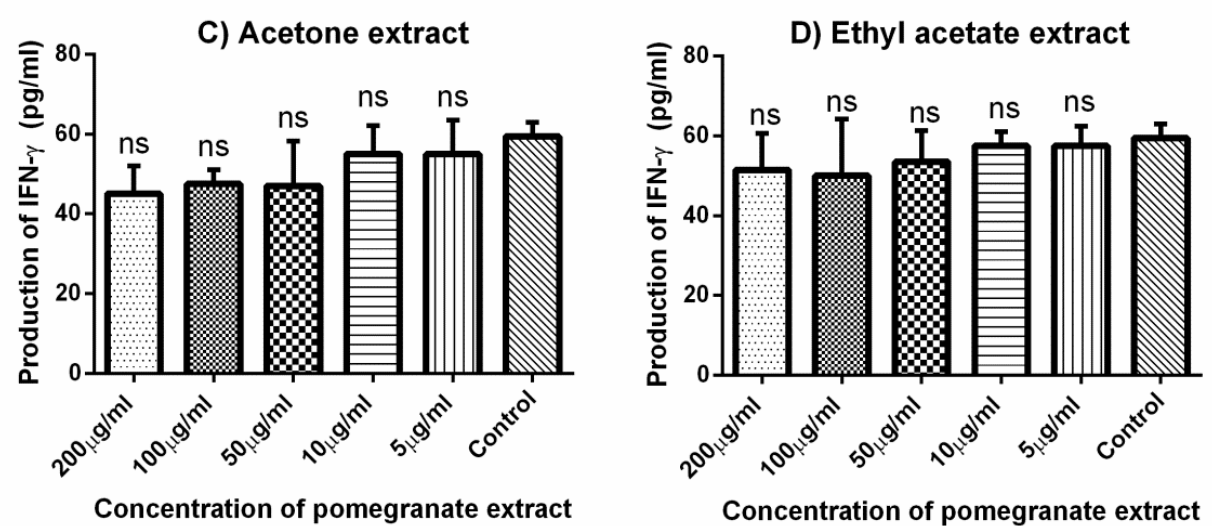

Figure 1:- IFN- $\gamma$ production in PBMCs treated with P. granatum extracts. After $48 \mathrm{~h}$ of incubation PBMCswith several concentrations of P. granatum extracts cell culture supernatant was assayed for IFN- $\gamma$ by using a cytokine specific ELISA. A) Methanol extract, B) Aqueous extract, C) Acetone extract, D) Ethyl acetate extract. Data were analysed by one way ANOVA and $\mathrm{P}$ values are shown where the difference between responses of different treatments relative to the control were determined to be statistically significant. $* * * * \mathrm{P}<0.0001, * * * \mathrm{P}<0.001, * * \mathrm{P}$ $<0.01, * \mathrm{P}<0.05$, ns $\mathrm{P} \geq 0.05$ (not significant). 
Interleukin-4 (IL-4):-

Treatment of PBMCs with concentration between $10-200 \mu \mathrm{g} / \mathrm{ml}$ of methanol and aqueous extracts resulted in a significant increase in IL-4 production when compared with untreated cells (Figure $2 \mathrm{~A} \& \mathrm{~B}$ ). $50 \mu \mathrm{g} / \mathrm{ml}$ concentration of methanol extract and 10- $50 \mu \mathrm{g} / \mathrm{ml}$ of aqueous extract are the most effect doses. Acetone and Ethyl acetate extracts showed no significant difference in IL-4 production (Figure 2 C\&D) compared to untreated cells (control).
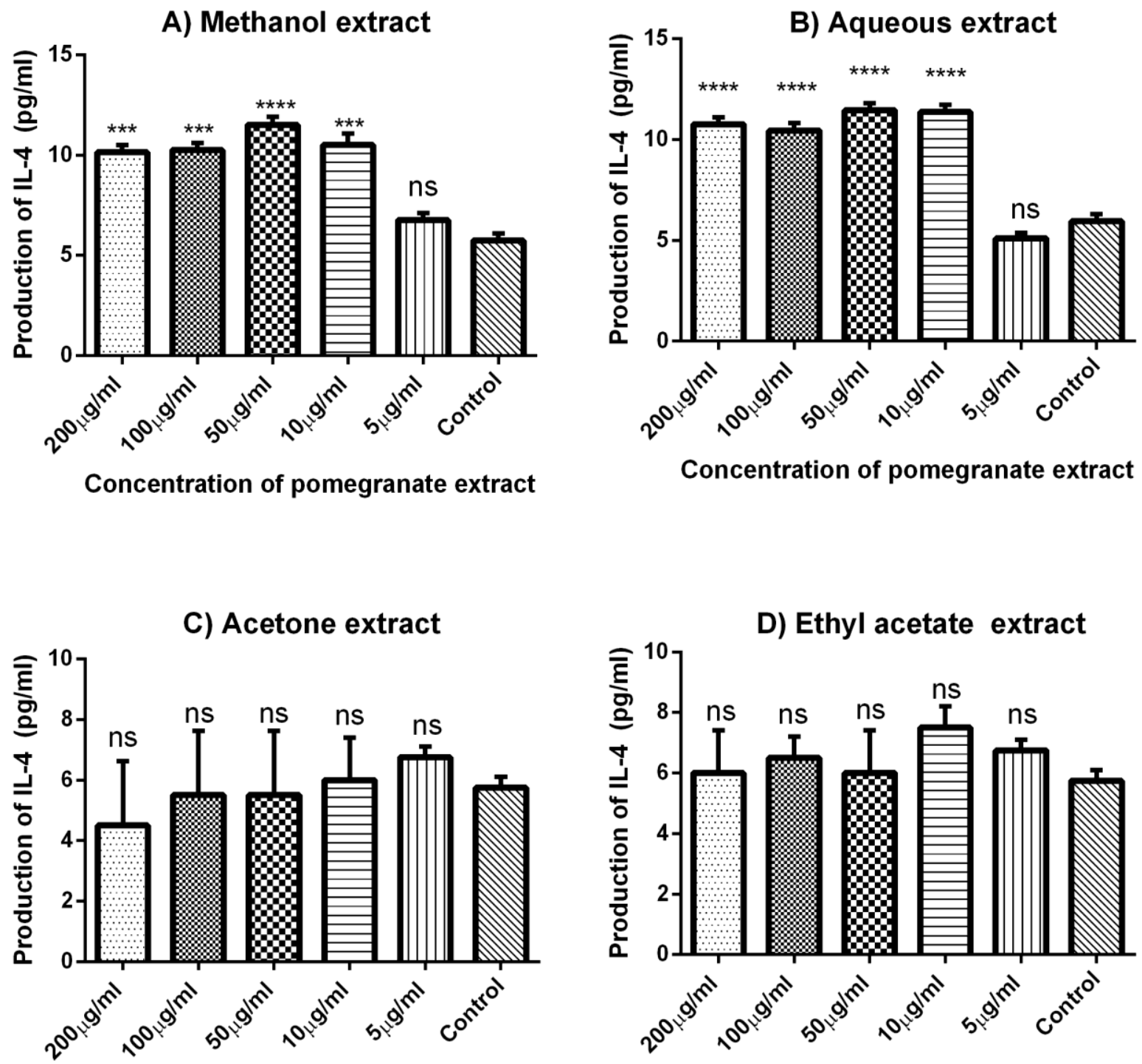

Concentration of pomegranate extract

Concentration of pomegranate extract

Figure 2:- IL-4 production in PBMCs treated with P. granatum extracts. After $48 \mathrm{~h}$ of incubation PBMCs with several concentrations of $\mathrm{P}$. granatum extracts cell culture supernatant was assayed for IL-4 by using a cytokine specific ELISA. A) Methanol extract, B) Aqueous extract, C) Acetone extract, D) Ethyl acetate extract. Data were analysed by one way ANOVA and $\mathrm{P}$ values are shown where the difference between responses of different treatments relative to the control were determined to be statistically significant. $* * * * \mathrm{P}<0.0001$, $* * * \mathrm{P}<0.001, * * \mathrm{P}$ $<0.01, * \mathrm{P}<0.05$, ns $\mathrm{P} \geq 0.05$ (not significant). 
Interleukin-10 (IL-10):-

Treatment PBMCs with highest concentration (100-200 $\mu \mathrm{g} / \mathrm{ml})$ of methanol extract and $(200-\mu \mathrm{g} / \mathrm{ml})$ of aqueous extract exhibited significant enhancement in IL-10 production when compared to untreated cells (Error! Reference source not found. A\&B). Acetone and Ethyl acetate extracts exhibited no significant difference in IL-4 production (Error! Reference source not found. C\&D) compared to untreated cells (control).

\section{A) Methanol extracts}

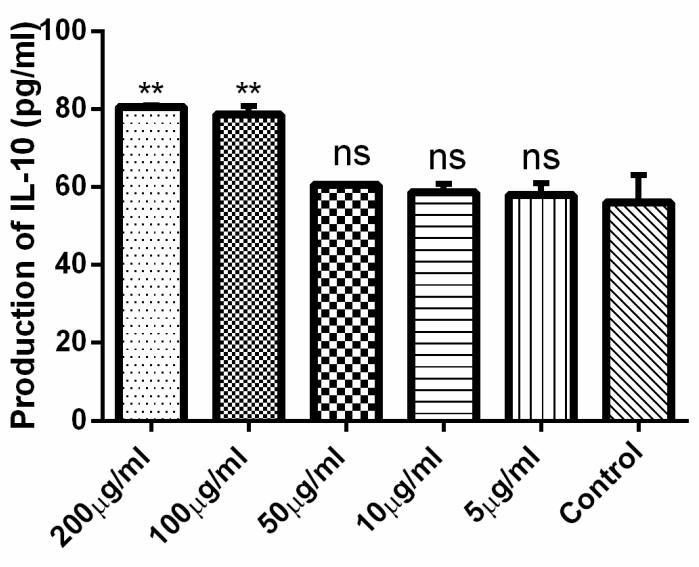

Concentration of pomegranate extract

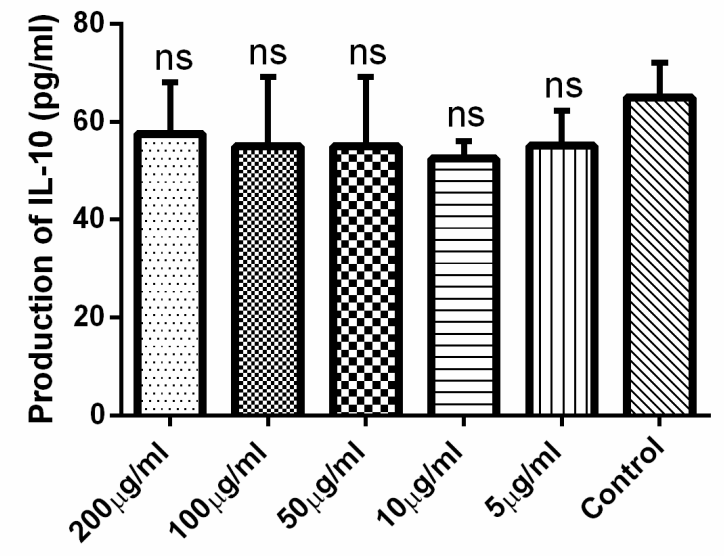

Concentration of pomegranate extract

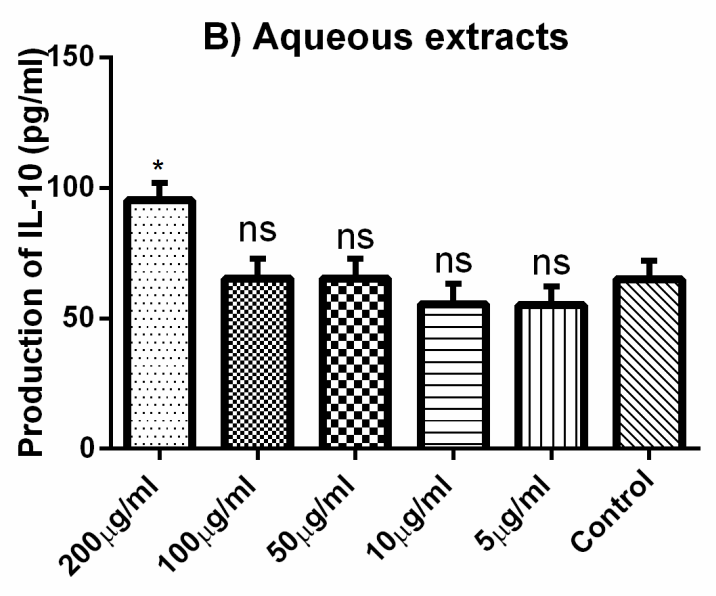

Concentration of pomegranate extract

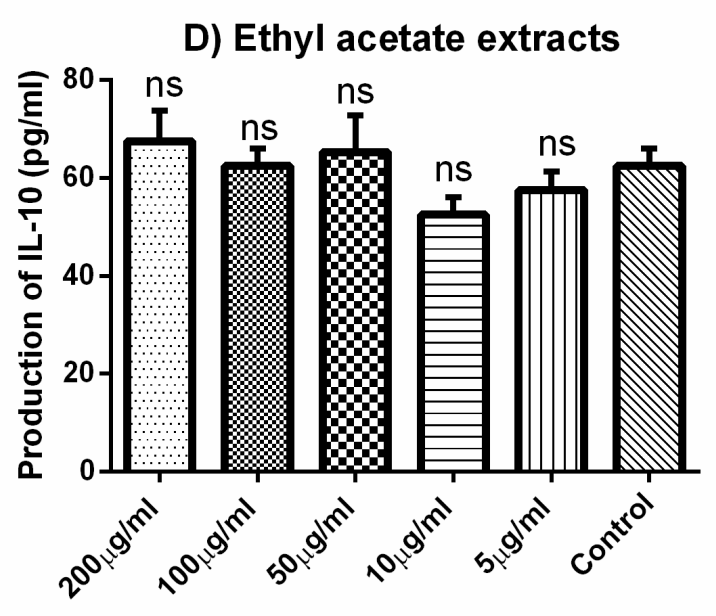

Concentration of pomegranate extract

Figure 3:- IL-10 production in PBMCs treated with $P$. granatum extracts. After $48 \mathrm{~h}$ of incubation PBMCs with several concentrations of $P$. granatum extracts cell culture supernatant was assayed for IL-10 by using a cytokine specific ELISA. A) Methanol extract, B) Aqueous extract, C) Acetone extract, D) Ethyl acetate extract. Data were analysed by one way ANOVA and $\mathrm{P}$ values are shown where the difference between responses of different treatments relative to the control were determined to be statistically significant. $* * * * \mathrm{P}<0.0001, * * * \mathrm{P}<0.001,{ }^{*} * \mathrm{P}$ $<0.01,{ }^{*} \mathrm{P}<0.05$, ns $\mathrm{P} \geq 0.05$ (not significant). 
Transforming growth factor beta (TGF- $\beta$ ):-

Treatment PBMCs with $5-200 \mu \mathrm{g} / \mathrm{ml}$ of methanol extract, $10-200 \mu \mathrm{g} / \mathrm{ml}$ of aqueous extract, $50-200 \mu \mathrm{g} / \mathrm{ml}$ of acetone extract and $200 \mu \mathrm{g} / \mathrm{ml}$ of ethyl acetate extract showed significant increase in the production of TGF- $\beta$ when compared with those untreated cells (

A) Methanol extracts

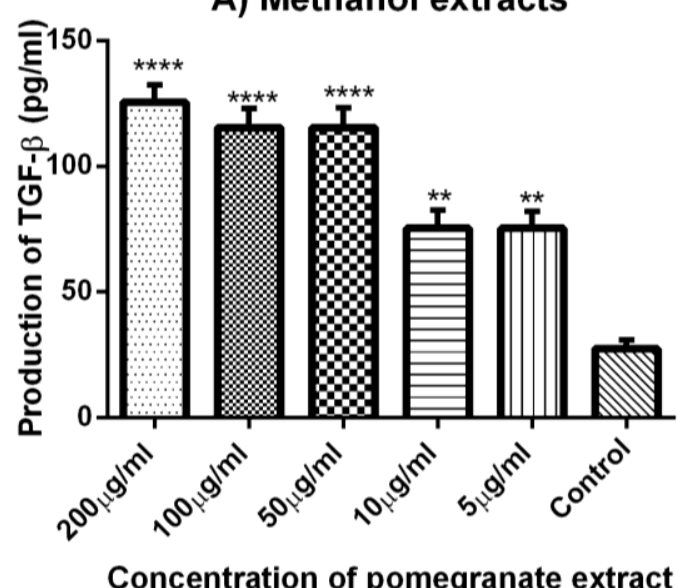

Concentration of pomegranate extract

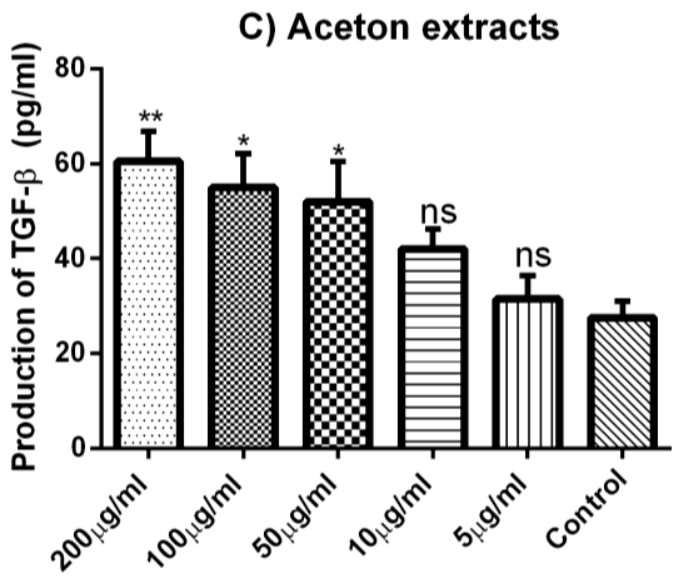

Concentration of pomegranate extract

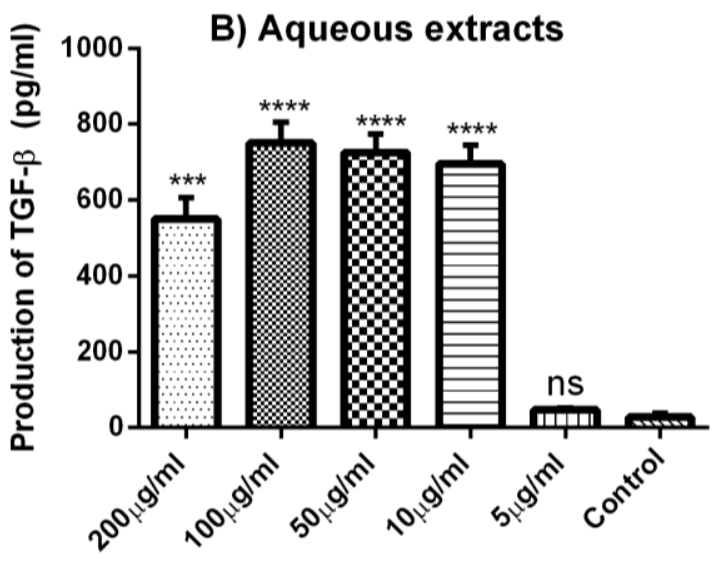

Concentration of pomegranate extract

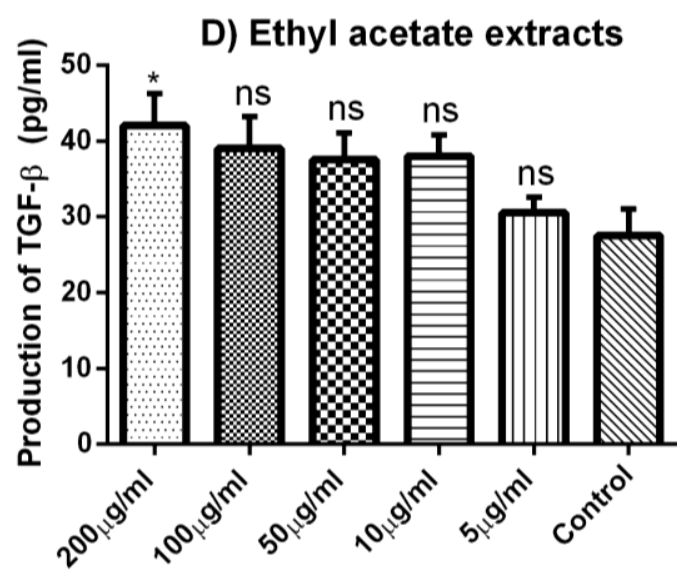

Concentration of pomegranate extract

Figure 4 A-D). Best doses of extracts was $200 \mu \mathrm{g} / \mathrm{ml}$ of methanol, acetone and ethyl acetate extracts and $100 \mu \mathrm{g} / \mathrm{ml}$ of aqueous extract. 


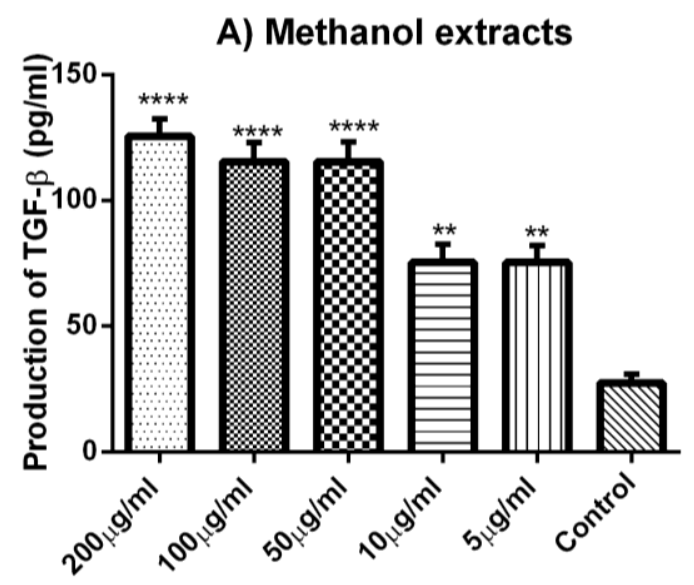

Concentration of pomegranate extract

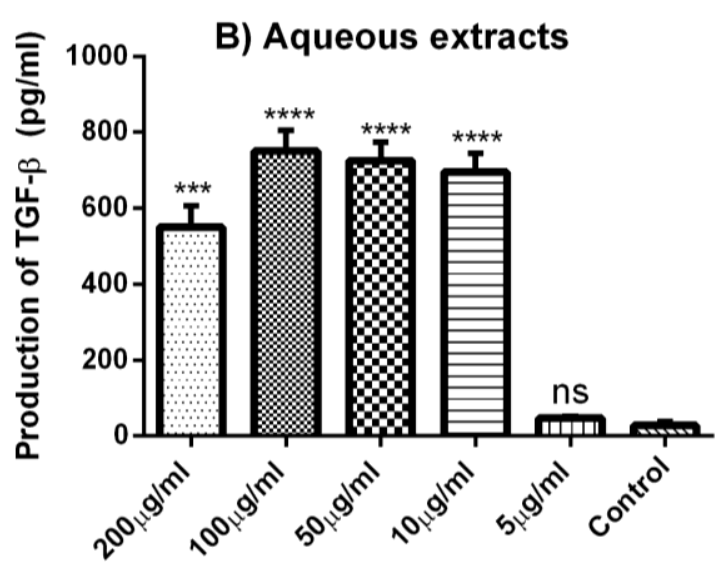

Concentration of pomegranate extract

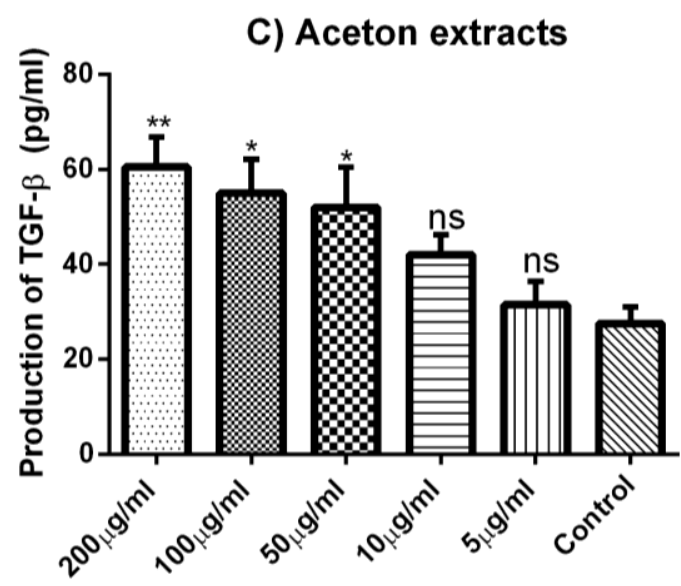

Concentration of pomegranate extract

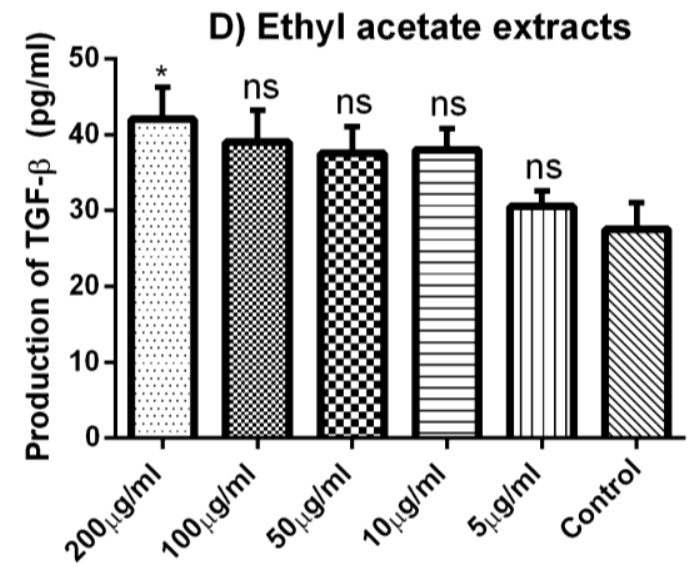

Concentration of pomegranate extract

Figure 4:- TGF- $\beta$ production in PBMCs treated with $\boldsymbol{P}$. granatum extracts. After $48 \mathrm{~h}$ of incubation PBMCs with several concentrations of $P$. granatum extracts cell culture supernatant was assayed for TGF- $\beta$ by using a cytokine specific ELISA. A) Methanol extract, B) Aqueous extract, C) Acetone extract, D) Ethyl acetate extract. Data were analysed by one way ANOVA and $\mathrm{P}$ values are shown where the difference between responses of different treatments relative to the control were determined to be statistically significant. $* * * * \mathrm{P}<0.0001$, **** $<$ $0.001, * * \mathrm{P}<0.01, * \mathrm{P}<0.05$, ns $\mathrm{P} \geq 0.05$ (not significant).

\section{Discussion:-}

Punica granatum peel extracts have been used in the traditional medicine for several medicinal properties [14]. Nowadays, there is a great interest in $P$. granatum extracts because of their potential therapeutic properties [15]. Current research appeared to show the most therapeutically valuable Punica granatum constituents which are estrogenic flavonols, ellagic acid ellagitannins, anthocyanins punicic acid, flavonoids, anthocyanidins, and flavones[11]. These constituents have several properties include anti-inflammatory[16], anti-oxidative[17], anticancer [18], anti-angiogenesis[19], inhibitory effect on apoptosis[20], and stimulation of cell differentiation[21].

In this study, we examine whether methanol, aqueous, acetone, ethyl acetate $P$. granatum peelextracts effects on the type 1 helper T cells (Th1) cytokine IFN- $\gamma$, the type 2 helper T cells (Th2) cytokines IL-10 and IL- 4 andregulatory T cells cytokine TGF- $\beta$ production at the cellular levels in PBMC of patients with Rheumatoid arthritis (RA).

The data from the current study showed that both $P$. granatum methanol and aqueous extracts alter the cytokine production pattern in PBMC of patients with RA when compared to $P$. granatum acetone and ethyl acetate 
extracts. Furthermore, the results revealed that some concentration of $P$. granatum methanol and aqueous extracts, particularly $10-200 \mu \mathrm{g} / \mathrm{ml}$ and $100-200 \mu \mathrm{g} / \mathrm{ml}$ respectively reduce IFN- $\gamma$ production significantly (Figure 1 A\& B) and this drop might contribute in suppression of T-cell expansion. P. granatum acetone and ethyl acetate extracts did not showed any significant difference in IFN- $\gamma$ production ((Figure 1 C\&D). In this study, P. granatum methanol and aqueous extracts in ranges $(10-200 \mu \mathrm{g} / \mathrm{ml})$ increased IL-4 production significantly (Figure 2 A\& B), this could be related to the expansion of B cells as IL-4 is an important B cell survival and growth factor [22]. IL-4 stimulates the development of type 2 helper T cells (Th2) and inflammation nevertheless could be inhibited by TGF$\beta$ and IL-10 cytokines [23]. The results also showed that, $P$. granatum methanol, aqueous and acetone extractshad extraordinary positive effect on TGF- $\beta$ and IL-10 release. Overall, $P$. granatum methanol and aqueous extracts significantly increase the level of IL-4, IL-10 and TGF- $\beta$ production (Figure 1-4); as a results of IL-10 and TGF- $\beta$ suppressive and regulatory function the cells environment could not change to inflammatory condition and changes to anti-inflammatory condition[24]. Furthermore, Methanol and aqueous extracts were more effective than acetone, and ethyl acetate for alter the cytokine production pattern in PBMCs. Researcher showed same results in cytokine production alterations made by $P$. granatum ingredients as the results obtained from present study; some concentration of $P$. granatum upregulated IL-10 and IL-4 production and by that might have susceptibility to the immunomodulatory activity $[25,26]$.

Furthermore, additional study showed that $P$. granatum extracts significantly reduced the expression levels of interferon (IFN) $\gamma$ as well as inducible nitric oxide synthase (iNOS) of the mice following $P$. granatum treatment compared to the untreated controls[27]. Several studies have reported significant anti-inflammatory activity of $P$. granatum and some conclusions could be drawn from all the studies Firstly, the pure compounds occurring in $P$. granatum extract appear to act through different pathways. methanol and aqueous extracts from $P$. granatum peel could inhibit the expression and secretion of several inflammatory mediators such as IL-6, IL-8, MCP-1, iNOS, COX-2, and $\mathrm{PGE}_{2}[28]$. Additionally to these conclusions, there are some other studies that indicate $P$. granatum peel extracts might affect immune responses, for example a study of $P$. granatum contents exhibited inhibition of inducible nitric oxide synthase (iNOS) expression and NO production in in RAW 264.7 cells [29].

In conclusion, the current study provide evidence to show that bioavailable constituents of $P$. granatum exert an anti-inflammatory effect. This additionally suggests that consumption of $P$. granatum might be of value in inhibiting production of inflammatory mediators in arthritis.

\section{Acknowledgement:-}

This work was financially supported by Taif University (Project No. 1/437/5024).

\section{References:-}

1. Burska, A.N., et al., Gene expression analysis in RA: towards personalized medicine. The Pharmacogenomics Journal, 2014. 14(2): p. 93-106.

2. Zangerle, P.F., et al., Direct stimulation of cytokines (IL-1 $\beta$, TNF- $\alpha$, IL-6, IL-2, IFN- $\gamma$ and GM-CSF) in whole blood: II. Application to rheumatoid arthritis and osteoarthritis. Cytokine, 1992. 4(6): p. 568-575.

3. Feldmann, M., et al., The rationale for the current boom in anti-TNF $\alpha$ treatment. Is there an effective means to define therapeutic targets for drugs that provide all the benefits of anti-TNF $\alpha$ and minimise hazards? Annals of the Rheumatic Diseases, 1999. 58(suppl 1): p. I27-I31.

4. Fox, D.A., The role of $\mathrm{T}$ cells in the immunopathogenesis of rheumatoid arthritis: new perspectives. Arthritis Rheum, 1997. 40(4): p. 598-609.

5. Abbas, A.K., K.M. Murphy, and A. Sher, Functional diversity of helper T lymphocytes. Nature, 1996. 383(6603): p. 787-93.

6. Khoury, S.J., W.W. Hancock, and H.L. Weiner, Oral tolerance to myelin basic protein and natural recovery from experimental autoimmune encephalomyelitis are associated with downregulation of inflammatory cytokines and differential upregulation of transforming growth factor beta, interleukin 4, and prostaglandin $\mathrm{E}$ expression in the brain. J Exp Med, 1992. 176(5): p. 1355-64.

7. Joosten, L.A., et al., Role of interleukin-4 and interleukin-10 in murine collagen-induced arthritis. Protective effect of interleukin-4 and interleukin-10 treatment on cartilage destruction. Arthritis Rheum, 1997. 40(2): p. 249-60.

8. Guidelines for the management of rheumatoid arthritis. American College of Rheumatology Ad Hoc Committee on Clinical Guidelines. Arthritis Rheum, 1996. 39(5): p. 713-22. 
9. Zochling, J., et al., Use of complementary medicines for osteoarthritis--a prospective study. Ann Rheum Dis, 2004. 63(5): p. 549-54.

10. Tabish, S.A., Complementary and Alternative Healthcare: Is it Evidence-based? International Journal of Health Sciences, 2008. 2(1): p. V-IX.

11. Jurenka, J.S., Therapeutic applications of pomegranate (Punica granatum L.): a review. Altern Med Rev, 2008. 13(2): p. 128-44.

12. Banihani, S., S. Swedan, and Z. Alguraan, Pomegranate and type 2 diabetes. Nutrition Research, 2013. 33(5): p. 341-348.

13. Bhowmik, D., et al., Medicinal uses of Punica granatum and its health benefits. Journal of Pharmacognosy and Phytochemistry, 2013. 1(5).

14. Longtin, R., The pomegranate: nature's power fruit? J Natl Cancer Inst, 2003. 95(5): p. 346-8.

15. Rahimi, H.R., M. Arastoo, and S.N. Ostad, A Comprehensive Review of Punica granatum (Pomegranate) Properties in Toxicological, Pharmacological, Cellular and Molecular Biology Researches. Iranian Journal of Pharmaceutical Research : IJPR, 2012. 11(2): p. 385-400.

16. Hollebeeck, S., et al., Anti-inflammatory effects of pomegranate (Punica granatum L.) husk ellagitannins in Caco-2 cells, an in vitro model of human intestine. Food Funct, 2012. 3(8): p. 875-85.

17. Singh, R.P., K.N. Chidambara Murthy, and G.K. Jayaprakasha, Studies on the antioxidant activity of pomegranate (Punica granatum) peel and seed extracts using in vitro models. J Agric Food Chem, 2002. 50(1): p. 81-6.

18. Jeune, M.A., J. Kumi-Diaka, and J. Brown, Anticancer activities of pomegranate extracts and genistein in human breast cancer cells. J Med Food, 2005. 8(4): p. 469-75.

19. Dana, N., S.H. Javanmard, and L. Rafiee, Antiangiogenic and antiproliferative effects of black pomegranate peel extract on melanoma cell line. Research in Pharmaceutical Sciences, 2015. 10(2): p. 117-124.

20. Sineh Sepehr, K., et al., Growth-Inhibitory and Apoptosis-Inducing Effects of Punica granatum L. var. spinosa (Apple Punice) on Fibrosarcoma Cell Lines. Advanced Pharmaceutical Bulletin, 2014. 4(Suppl 2): p. 583-590.

21. Kawaii, S. and E.P. Lansky, Differentiation-promoting activity of pomegranate (Punica granatum) fruit extracts in HL-60 human promyelocytic leukemia cells. J Med Food, 2004. 7(1): p. 13-8.

22. Zamorano, J., et al., Costimulation of resting B lymphocytes alters the IL-4-activated IRS2 signaling pathway in a STAT6 independent manner: implications for cell survival and proliferation. Cell Res, 2001. 11(1): p. 44-54.

23. Sehra, S., et al., IL-4 regulates skin homeostasis and the predisposition towards allergic skin inflammation. Journal of immunology (Baltimore, Md. : 1950), 2010. 184(6): p. 3186-3190.

24. Levings, M.K., et al., The role of IL-10 and TGF-beta in the differentiation and effector function of T regulatory cells. Int Arch Allergy Immunol, 2002. 129(4): p. 263-76.

25. Rasheed, Z., et al., Polyphenol-rich pomegranate fruit extract (POMx) suppresses PMACI-induced expression of pro-inflammatory cytokines by inhibiting the activation of MAP Kinases and NF- $\mathrm{B}$ in human KU812 cells. Journal of Inflammation, 2009. 6(1): p. 1.

26. BenSaad, L.A., et al., Anti-inflammatory potential of ellagic acid, gallic acid and punicalagin A\&B isolated from Punica granatum. BMC Complementary and Alternative Medicine, 2017. 17: p. 47.

27. Mubaraki, M.A., et al., Beneficial effect of Punica granatum peel extract on murine malaria-induced spleen injury. BMC Complementary and Alternative Medicine, 2016. 16: p. 221.

28. Colombo, E., E. Sangiovanni, and M. Dell'Agli, A Review on the Anti-Inflammatory Activity of Pomegranate in the Gastrointestinal Tract. Evidence-Based Complementary and Alternative Medicine, 2013. 2013: p. 11.

29. Lee, C.-J., et al., Anti-inflammatory effects of Punica granatum Linne in vitro and in vivo. Food Chemistry, 2010. 118(2): p. 315-322. 